\section{Genetic heterogeneity of CTX-M type extended-spectrum B-lactamase producing Escherichia coli strains from diverse sources in Saudi Arabia}

Sabry A. Hassan ${ }^{1,2 *}$, Youssuf A. Gherbawy1,3, Abdallah D. Altalhi ${ }^{1}$

1 Biology Department, Faculty of Science, Taif University 888, Taif, Saudi Arabia.

2 Microbiology Department, Faculty of Veterinary Medicine, South Valley University 83523, Qena, Egypt.

3 Botany Department, Faculty of Science, South Valley University 83523, Qena, Egypt.

Corresponding author:

\section{Dr. Sabry A. Hassan}

झ sabryh@|ycos.com
Background: The rise of CTX-M extended spectrum $\beta$-lactamase (ESBLs)-producing $E$. coli in non-human sources is a growing concern of public health. Understanding the extent of public health risk attributed to CTX-M type ESBLs-producing strains from different sources is critical for effective control.

Objective: This study focuses on detection and molecular typing of CTX-M type ESBL-producing E. coli isolated from various sources in Taif, Western Saudi Arabia.

Material and Methods: A total of 24 E. coli ESBLs-producing isolates from multiple sources were assessed for the presence of CTX-M groups gene by PCR, and subsequently their clonal relatedness by random amplified of polymorphic DNA (RAPD) analysis. Isolates were selected according to a resistance phenotype consistent with production of ESBL-type beta-lactamase using double disk diffusion method.

Results: A CTX-M gene was detected in all 24 isolates. RAPD typing of E. coli isolates bearing CTX-M gene showed 24 patterns verified into two major clusters (A, B) and three sub-clusters (A1 - A3). Phylogenetic analysis indicating a degree of similarity among clustering isolates from human, sheep and raw milk origins. Identical profile was observed between three isolates obtained from pet bird and chicken. 
Conclusion: This study demonstrates occurrence and diversity of ESBLCTX-M producing E. coli isolates from multiple sources in Saudi Arabia. The study also shows a non-clonal dissemination, despite the fact that many isolates revealed some degrees of genetic relatedness.

Keywords: Molecular typing; E. coli; CTX-M type ESBLs; RAPD-PCR

\section{Introduction}

Escherichia coli strains are greatly important in human and animals intestinal and extraintestinal infections. For the treatment of their infections, $\beta$-lactam antibiotics are widely used [1]. Production of beta-Lactamases are the commonest cause of bacterial resistance to beta-lactam antibiotics, which are encoded chromosomally or on plasmids and inactivate $\beta$-lactams by hydrolyzing the $\beta$-lactam ring.

The spread of resistance to extended-spectrum cephalosporins (ESCS) used in human and veterinary medicine causes major therapeutic challenges worldwide [2]. Recently, the rapid dissemination of extended-spectrum $\beta$-lactamases (ESBLs) in E.coli is becoming a problem due to the wide spread of the CTX-M enzymes.

The emergence of bla CTX-M $_{\text {has }}$ been detected in food animal populations [3], food products [4], and both domestic [5] and wild [6] animal species throughout the world. Saudi Arabia is one of many countries with higher rates of bacterial pathogens with ESBLs-producers in the clinical setting, mostly associated with CTX-M-types [7, 8].

Non-human sources can play an important role in the ecology of antibiotic resistant $E$. coli, and these may serve as an important reservoir of bacterial resistance. Therefore, a comprehensive understanding of the epidemiology of antimicrobial resistant bacteria and the contribution of different sources to the infections with resistant strains are crucial for effective control [9]. Unfortunately, few data is available for comparisons of the ESBLsproducing $E$. coli isolates from representative samples of domestic livestock and poultry, wildlife, and humans within the same geographic region.

The aim of this study was to characterize the genetic diversity of $E$. coli isolates from multiple sources within the same geographic region producing ESBLs and CTX-M using RAPD-PCR.

\section{Materials and Methods}

Bacterial Strains: A total of $24 \mathrm{E}$. coli isolates producing ESBLs were selected from a collection of 103 E. coli isolates obtained from various sources (human \& animal ) over a period of one-year (2014). The isolates were identified by biochemical reactions using API 20 E system (bioMerieux, Marcy l'Etoile, France) and confirmed by speciesspecific PCR amplification of the uspA gene [10]. Preliminary antibiotic susceptibility testing done according to the guidelines and recommendations CLSI [11]. The isolates that were characterized had 


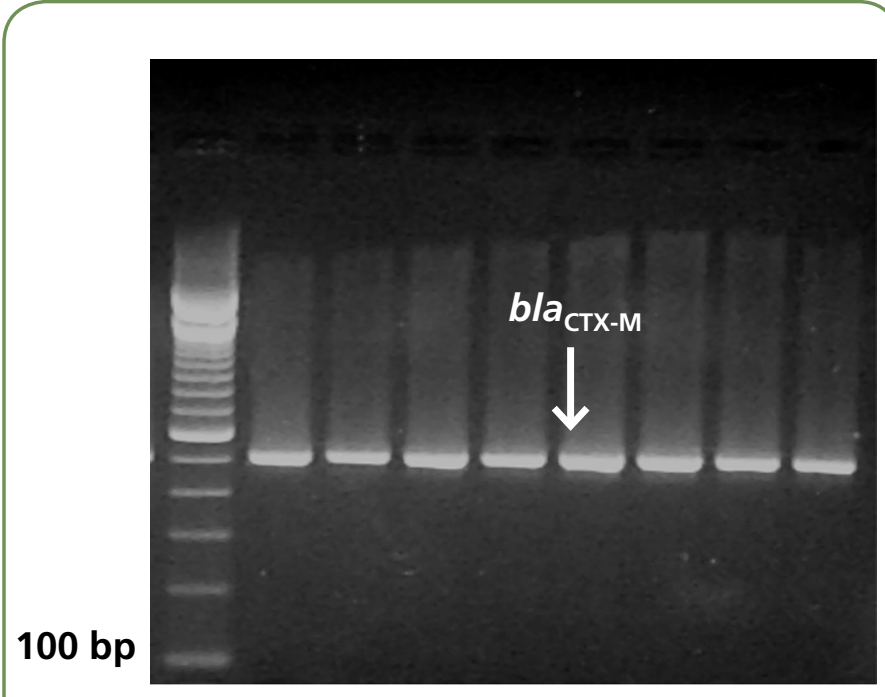

Figure 1. The result of the PCR amplification of the DNA target gene loci of 593-bp fragment DNA region coding for CTX-M groups. First Lane is a 100 bp DNA Ladder.

an ESBLs phenotype with reduced susceptibility to third generation cephalosporin's, with clavulanic acid synergy [12].

Genomic DNA preparation: The DNA of bacterial cells was extracted by a boiling technique that includes heating at boiling of an overnight bacterial culture $(200 \mu \mathrm{l})$ mixed with $800 \mu \mathrm{l}$ of distilled water, followed by cooling, centrifugation and the supernatant was used as the DNA template for the PCR.

\section{Genetic identification of CTX-M ESBLs:} The ESBLs-producer isolates were assessed for the presence of CTX-M type ESBLs gene by multiplex PCR assay using universal primer CTX-M-F: ATGTGCAGYACCAGTAARGTKATGGC; CTX-M-R: TGGGTRAARTARGTSACCAGAAYCAGCGG, with product size (593 bp) [13]. The cycling parameters of CTX-M specific PCR were as follows: an initial denaturation at $95^{\circ} \mathrm{C}$ for $15 \mathrm{~min}$; followed by 30 cycles of $94^{\circ} \mathrm{C}$ for $30 \mathrm{~s}, 62^{\circ} \mathrm{C}$ for $90 \mathrm{~s}$, and $72^{\circ} \mathrm{C}$ for $60 \mathrm{~s}$; and with a final extension at $72^{\circ} \mathrm{C}$ for $10 \mathrm{~min}$.

Clonal analysis by RAPD-PCR: The clonal relatedness was investigated by randomly amplified polymorphic DNA (RAPD-PCR) analysis as described by Williams et al. [14], using primers OPA10 (5'-d GTG ATCGCAG -3'), OPA11 (5'-d CAATCGCCGT-3') and M13 (5'-dGAGGGTGGCGGTTCT-3'). RAPD amplification condition consisted of: initial denaturation at $94^{\circ} \mathrm{C}$ for 5 minutes, followed by 40 cycles of denaturation ( 1 minute at $94^{\circ} \mathrm{C}$ ), annealing $\left(1\right.$ minute at $36^{\circ} \mathrm{C}$ ) and extension $\left(72^{\circ} \mathrm{C}\right.$ for 2 minutes), and a final extension step $\left(72^{\circ} \mathrm{C}\right.$ for 10 minutes). DNA fingerprints of RAPD were compared by visual inspection and considered unique when they differed by at least one band, irrespectively of band intensity. Dendrogram based on RAPD results were constructed by the unweighted pair group method with arithmetic average based on Jaccard's Similarity Coefficient, and by using Phoretix 1D Advanced V5.20 software (Nonlinear Dynamics, Newcastle upon Tyne, UK). PCR amplification reactions were performed in a volume of $25 \mu \mathrm{l}$ containing $12.5 \mu \mathrm{l}$ of $2 x$ GoTaq ${ }^{\circledR}$ Green Master Mix (Promega, Madison, WI, USA) and $2 \mu$ of genomic DNA template. Amplified PCR products were separated using $1.4 \%$ agarose gels, visualized and photographed by G: BOX gel documentation (SYN GENE, Cambridge, UK). A 100 bp DNA ladder (Promega) was used as molecular weight.

\section{Results}

Identity of $\boldsymbol{E}$. coli isolates: All 24 isolates were confirmed as $E$. coli by generating the 884bp E. coli-specific product using species-specific PCR amplification of the universal stress protein A (uspA).

Antimicrobial susceptibility: The results of antibiogram testing revealed that all E. coli 24 isolates were resistant to one or more cephalosporins, but none of them were resistant to cefoxitin / imipenem or both.

ESBLs and CTX-M- production: Based on PCR assay of $24 E$. coli isolates with phenotypically confirmed ESBLs production, yielded a positive amplicon with CTX-M universal primer (Fig. 1). 


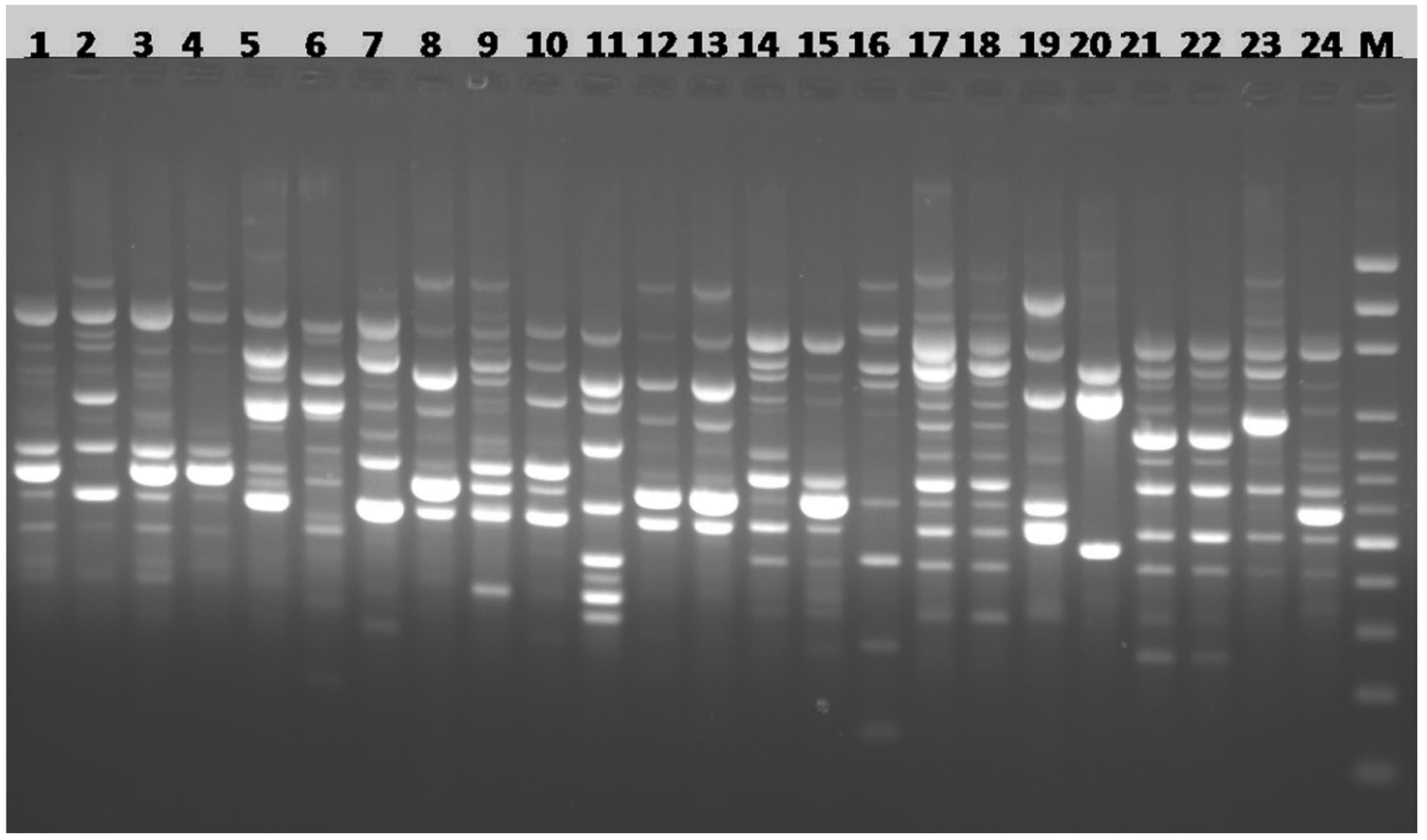

Figure 2. Random amplified polymorphic DNA patterns obtained by using the primer OPA10 ( $5^{\prime}-d$ GTG ATCGCAG - $\left.3^{\prime}\right)$ from different $E$. coli strains isolated from sheep (lanes 1 - 4), chicken (lanes 5-10), wild bird (lanes 11-14), milk (lanes 15-18), human (lanes 19 -22) and cattle (lanes 23 \& 24). Lane M is a 100 bp DNA Ladder.

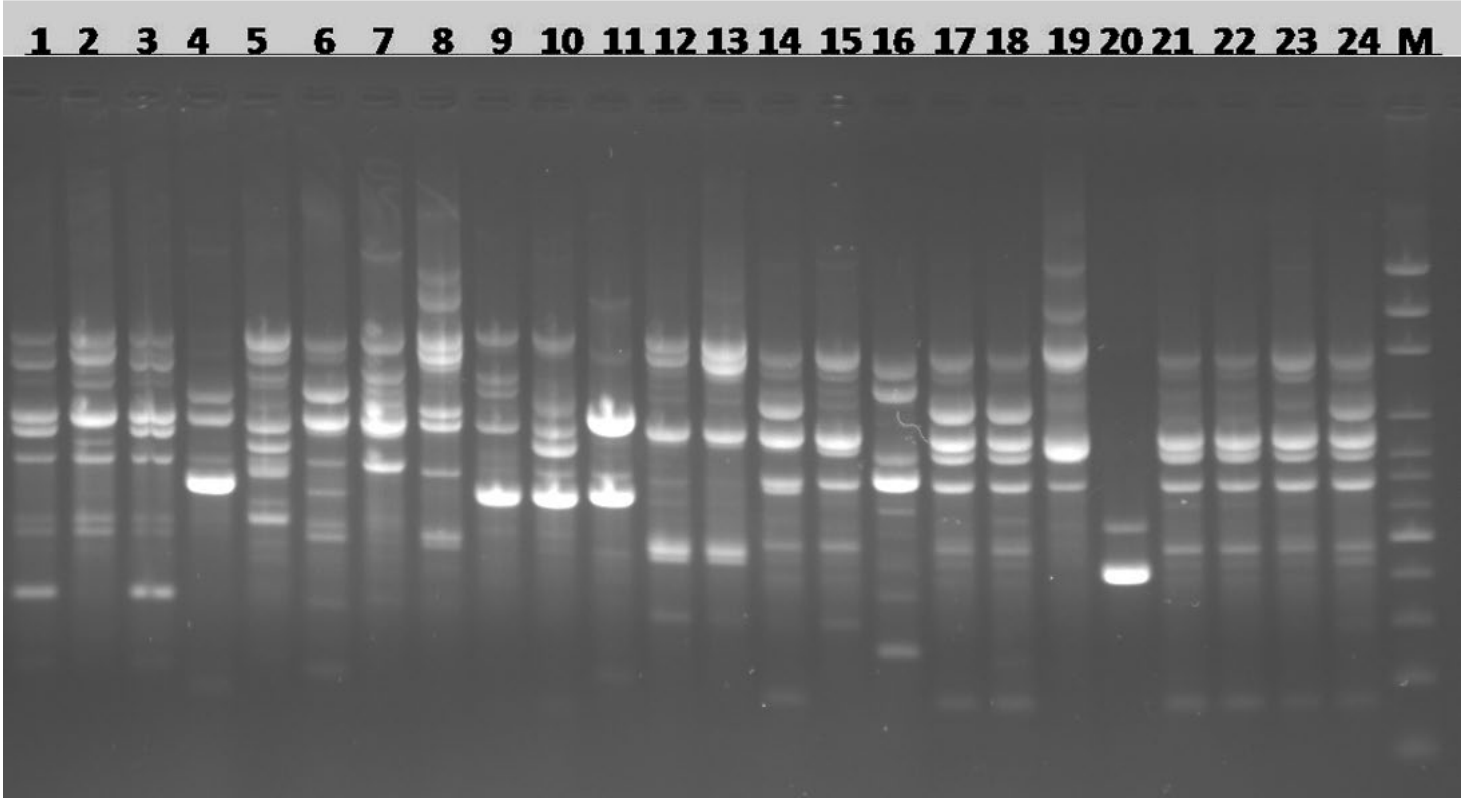

Figure 3. Random amplified polymorphic DNA patterns obtained by using the primer OPA 11 ( $5^{\prime}-d$ CAATCGCCGT-3') from different Escherichia coli strains isolated from sheep (lanes 1 - 4), chicken (lanes 5-10), wild bird (lanes 11-14), milk (lanes 1518), human (lanes 19 -22) and cattle (lanes 23 \& 24). Lane M is a 100 bp DNA Ladder. 


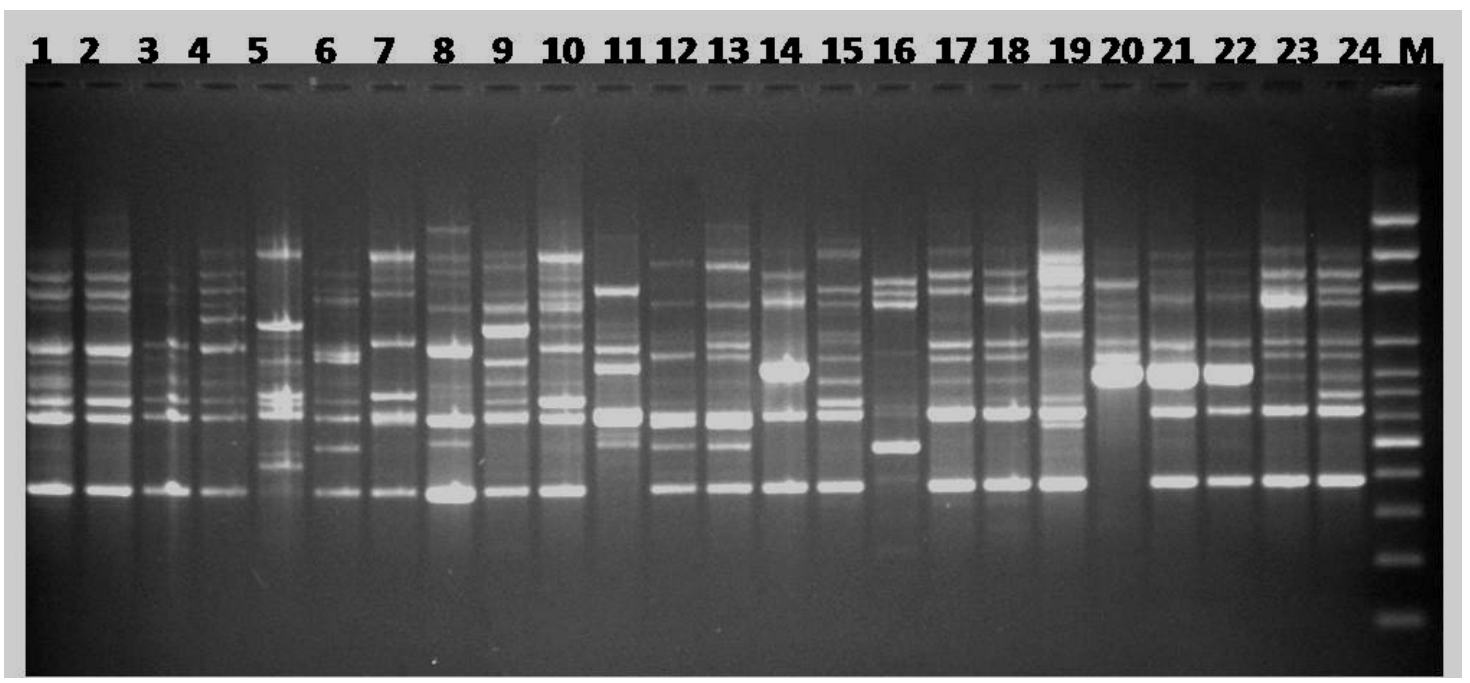

Figure 4. Random amplified polymorphic DNA patterns obtained by using the primer M13 (5'-dGAGGGTGGCGGTTCT-3') from different Escherichia coli strains isolated from sheep (lanes 1 - 4), chicken (lanes 5-10), wild bird (lanes 11-14), milk (lanes 15-18), human (lanes 19 -22) and cattle (lanes 23 \& 24). Lane M is a 100 bp DNA Ladder

Clonal analysis: The genomic diversity analysis of 24 ESBLS, CTX-M producing isolates of $E$. coli using the RAPD-PCR fingerprinting method with three-type primers a shown in (Figs. 2-4). The RAPD-PCR profiles allowed differentiation of the 24 isolates and a complex pattern of fingerprints have been obtained for all isolates. Generally, the electrophoretic analysis of the PCR reaction products has revealed that the number of bands ranged from 4-14 bands, and the sizes of the PCR products ranged from 0.2 to $1.4 \mathrm{~kb}$.

The combined results of the three primers were used to construct dendrogram showing the relationships among the studied isolates (Fig. 5). The dendrogram has grouped the 24 strains of $E$. coli into two major clusters ( $A$ and $B$ ) and three sub-clusters (A1-A3). Phylogenetic analysis of RAPD profile revealed that isolates from chicken (ST8) and pet birds (ST12, ST13) origins were identical. The remaining of isolates showed mixed RAPD patterns. Even though there was no complete homology among the isolates, two human strains (ST 21 and ST22) were grouped with one isolate from raw milk with a similarity index of $80 \%$, indicating some degree of relatedness. The other human isolates were grouped with isolates from pets and chicken with less similarity index (60\%) and (30\%), respectively.

\section{Discussion}

This study presents the epidemiology of $E$. coli isolates harboring CTX-M-group from various sources within one geographic region of Saudi Arabia. All ESBLs-positive isolates were analyzed for bla $_{\text {CTX-M }}$ genes using PCR assay. The results showed

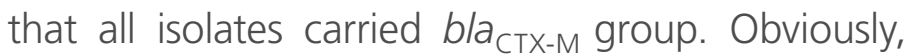
this group is the most common among ESBLsproducing E. coli in Saudi Arabia, and similar to most studies reported in the last years $[7,8]$. The ESBLs-producing E. coli had phenotypes consistent with production of CTX-M enzyme group.

During the last decade, strains of $E$. coli that producing ESBLs-CTX-M have emerged as a cause of serious human infections in many parts of the world $[15,16]$. CTX-M-type ESBLs have also recently become predominant among ESBLs-positive $E$. coli 


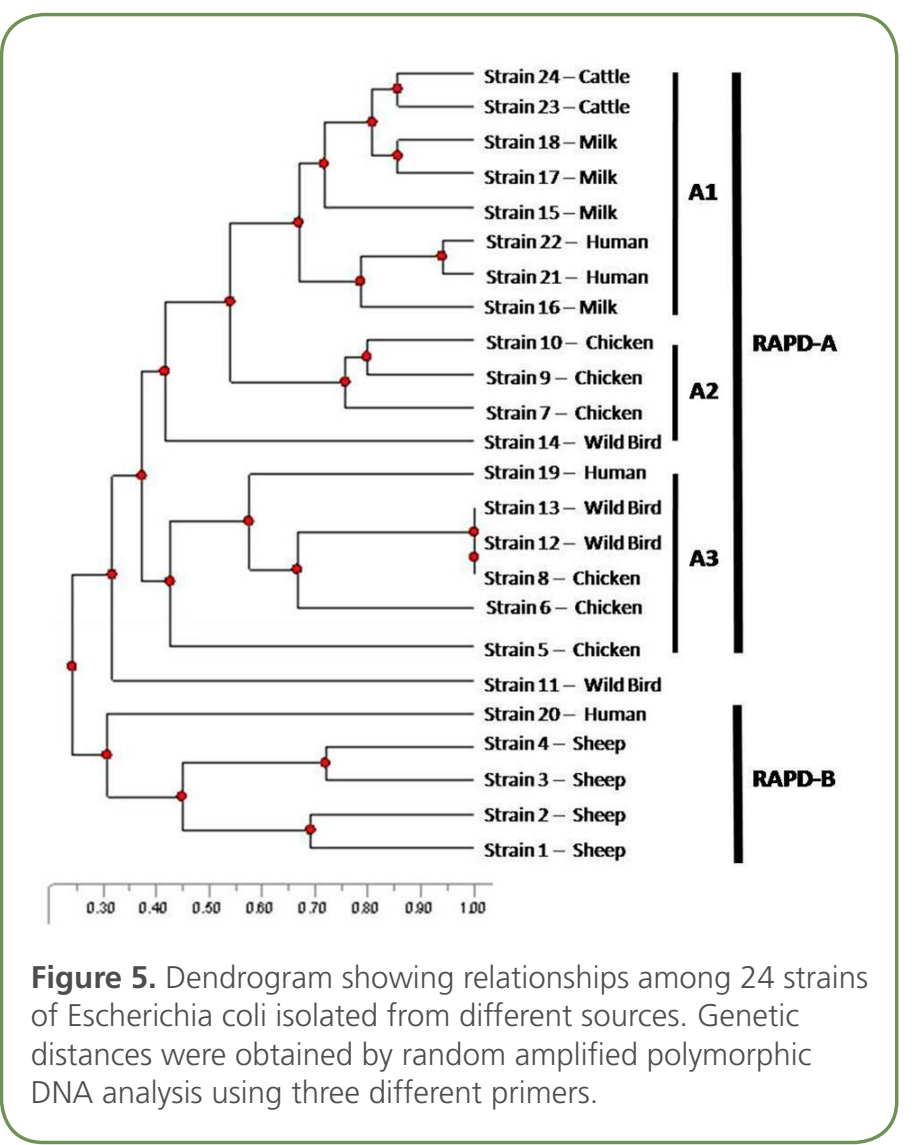

human clinical isolates in Middle East countries [17, 18]. Studies from USA, Europe and Asia have shown the recovery of bla CTX-M $_{\text {group from farm livestock }}$ with increasing frequency [19- 21]. The ESBLsCTX-M type was also reported in faecal samples of broilers [22], and healthy pets [23]. ESBLs-producing $E$. coli strains have been also identified in food animals [ 24-25] and wild animals [26].

According to our best knowledge there is no previous study in Saudi Arabia reported on the occurrence of E. coli ESBLs-producing CTX-M type from non-human sources. This study found no evidence of spread of $E$. coli CTX-M producers between animals and human within the same geographic region of Saudi Arabia. RAPD analysis of

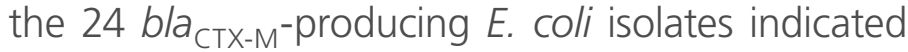
that there is no common clonal relationship between isolates. In this study, a total of 21 distinct profiles were obtained among 24 CTX-M- producing isolates which are indicating high genetic diversity. In agreement with our results, a recent study of Hu et al. [27], showed that the CTX-M-producing isolates from various sources have great diversity using other molecular typing methods. Additionally, the study of Al-Agamy et al. [28] in Saudi Arabia, indicated a high level of heterogeneity among their CTX-M-producing E. coli isolates from various human clinical samples in Riyadh hospitals. In Korea, Choi et al. [29] found no evidence of the spread of CTX-M-producing E. coli isolates between animal and humans.

On the other hand, some studies have found genotype similarities among CTX-M-producing $E$. coli isolates from animals, meat and humans [3032].

In Conclusion, this study shows high genetic diversity among isolates of $E$. coli producing bla CTX-M $_{\text {. }}$ genes suggesting non clonal dissemination among human and animal isolates.

\section{Acknowledgements}

The authors express their appreciation to the deanship of scientific research at Taif University for funding the work through research project number 1-435-3319. 


\section{References}

1. Horish RE. Ceftiofur use in food animals. Curr Top Med Chem 2002; 2: 717-731.

2. Naseer $U$, and Sundsfjord A. The CTX-M conundrum: dissemination of plasmids and Escherichia coli clones. Microb Drug Resist 2011; 17: 83-97.

3. Horton RA, Randall LP, Snary EL, Cockrem H, Lotz S, Wearing H, Duncan D, Rabie A, McLaren I, Watson E, La Ragione RM, Coldham NG. Fecal carriage and shedding density of CTX-M extended-spectrum \{beta\}-lactamase producing Escherichia coli in cattle, chickens, and pigs: Implications for environmental contamination and food production. Appl Environ Microbiol. 2011;77: 3715-9.

4. Doi Y, Paterson DL, Egea P, Pascual A, López-Cerero L, Navarro MD, Adams-Haduch JM, Qureshi ZA, Sidjabat HE, RodríguezBaño J. Extended-spectrum and CMY-type beta-lactamaseproducing Escherichia coli in clinical samples and retail meat from Pittsburgh, USA and Seville, Spain. Clin Microbiol Infect. 2010; 16: 33-38.

5. O'Keefe A, Hutton TA, Schifferli DM, Rankin SC. First detection of CTX-M and SHV extended-spectrum $\beta$-lactamases in Escherichia coli urinary tract isolates from dogs and cats in the United States. Antimicrob Agents Chemother. 2010; 54: 34893492.

6. Costa D, Poeta P, Sáenz Y, Vinué L, Rojo-Bezares B, Jouini A, Zarazaga M, Rodrigues J, Torres C. Detection of Escherichia coli harbouring extended-spectrum beta-lactamases of the CTX-M, TEM and SHV classes in faecal samples of wild animals in Portugal. J Antimicrob Chemother. 2006; 58: 1311-1312.

7. Radhouani H, Pinto L, Coelho C, Gonçalves A, Sargo R, Torres C, Igrejas G, Poeta P. Detection of Escherichia coli harbouring extended-spectrum $\beta$-lactamases of the CTX-M classes in faecal samples of common buzzards (Buteo buteo). J Antimicrob Chemother. 2010; 65: 171-173.

8. Bindayna KM, Khanfar HS, Senok AC, Botta GA. Production of CTX-M genotype among ESBL-isolates in a tertiary hospital in Saudi Arabia. Saudi Med J. 2010; 31:859-863.

9. Hassan $H$, and Abdalhamid B. Molecular characterization of extended-spectrum beta-lactamase producing Enterobacteriaceae in a Saudi Arabian tertiary hospital. J Infect Dev Ctries. 2014; 8(3): 282-288.

10. Chen J, and Griffiths NW. PCR differentiation of Escherichia coli from other gram-negative bacteria using primers derived from the nucleotide sequences flanking the gene encoding the universal stress protein. Lett Appl Microbiol. 1998; 27:369-371.

11. Clinical and Laboratory Standards Institute (CLSI). Performance Standards for Antimicrobial Susceptibility Testing; TwentyThird Informational Supplement. CLSI document M100-S23 (ISBN 1-56238-865-7 [Print]; ISBN 1-56238-866-5 [Electronic]). Clinical and Laboratory Standards Institute, 950 West Valley Road, Suite 2500, Wayne, Pennsylvania 19087 USA, 2013.

12. Pitout JD, Reisbig MD, Venter EC, Church DL, Hanson ND. Modification of the double-disk test for detection of Enterobacteriaceae producing extended spectrum and AmpC $\beta$-lactamases. J Clin Microbiol. 2003; 41: 3933-3935.

13. Fang $\mathrm{H}$, Ataker $\mathrm{F}$, Hedin $\mathrm{G}$, Dornbusch K. Molecular epidemiology of extended-spectrum-lactamases among Escherichia coli isolates collected in a Swedish hospital and its associated health care facilities from 2001 to 2006. J Clin Microbiol. 2008; 46(2): 707-712.

14. Williams JGK, Kubelik AR, Livak KJ, Rafalski JA, Tingey SV. DNA polymorphisms amplified by arbitrary primers are useful as genetic markers. Nucleic Acids Res. 1990; 18(22):6531-6535.

15. Wyllie DH, Baxter E, Morgan M, Bowller TC. Spread of multiresistance and extended-spectrum B-lactamases amongst urinary Escherichia coli in Oxford, UK. J Antimicrob Chemother. 2005; 56: 986-988.

16. Canton R, Coque TM. The CTX-M beta-lactamase pandemic. Curr Opin Microbiol. 2006; 9:466-475.

17. Baroud M, Araj GF, Matar GM. Spread of CTX-M-15 Extended Spectrum $\beta$-lactamases encoding genes among Enterobacteriaceae in the Middle Eastern Region. Int Arab J Antimicrob Agents 2011; 1(1): 1-6.

18. May A. Abu Salah, Eman F. Badran, Asem A. Shehabi. High incidence of multidrug resistant Escherichia coli producing CTXM-type ESBLs colonizing the intestine of Jordanian infants. Int Arab J Antimicrob Agents 2013; 3(4): 1-8.

19. Liebana E, Batchelor M, Hopkins KL, Clifton-Hadley FA, Teale CJ, Foster A, Barker L, Threlfall EJ, Davies RH. Longitudinal farm study of extended-spectrum beta-lactamase-mediated resistance. J Clin Microbiol. 2006; 44: 1630-1634.

20. Tian GB, Wang HN, Zou LK, Tang JN, Zhao YW, Ye MY, Tang JY, Zhang Y, Zhang AY, Yang X, Xu CW, Fu YJ. Detection of CTX-M-15, CTX-M-22, and SHV-2 extended-spectrum betalactamases (ESBLs) in Escherichia coli fecal-sample isolates from pig farms in China. Foodborne Pathog Dis. 2009; 6: 297-304.

21. Wittum TE, Mollenkopf DF, Daniels JB, Parkinson AE, Mathews $J$, Fry PR, Abley MJ, Gebreyes WA. CTX-M-type extendedspectrum beta-lactamases present in Escherichia coli from the feces of cattle in Ohio, United States. Foodborne Pathog Dis. 2010; 7(12): 1575-1579.

22. Costa $D$, Vinué L, Poeta $P$, Coelho AC, Matos $M$, Sáenz $Y$, Somalo S, Zarazaga M, Rodrigues J, Torres C. Prevalence of extendedspectrum beta-lactamase-producing Escherichia coli isolates in faecal samples of broilers. Vet Microbiol. 2009; 138: 339-344.

23. Costa D, Poeta P, Brinãas L., Sa'enz Y, Rodrigues J, Torres C. Detection of CTX-M-1 and TEM-52 beta-lactamases in Escherichia coli strains from healthy pets in Portugal. J. Antimicrob Chemother. 2004; 54: 960-961.

24. Duan RS, Sit THC, Wong SSY, Wong RCW, Chow KH, Mak GC, Ng LT, Yam WC, Yuen KY, Ho PL. Escherichia coli producing CTX-M-lactamases in food animals in Hong Kong. Microbes Drug Resist. 2006; 12: 145-148.

25. Zheng H, Zeng Z, Chen S, Liu Y, Yao Q, Deng Y, Chen X, LV L, Zhuo C, Chen Z, Liu JH. Prevalence and characterisation of CTX-M beta-lactamases amongst Escherichia coli isolates from healthy food animals in China. Int J Antimicrob Agents 2012; 39(4): 305-310.

26. Costa, D., Poeta P, Sa'enz $Y$, Vinue' $L$, Rojo-Bezares B, Jouini $A$, Zarazaga M, Rodrigues J., Torres C. Detection of Escherichia coli 
harbouring extended-spectrum-lactamases of the CTX-M, TEM and SHV classes in faecal samples of wild animals in Portugal. J Antimicrob Chemother. 2007; 59: 1311-1312.

27. Hu YY, Cai JC, Zhou HW, Chi D, Zhang XF, Chen WL, Zhang $\mathrm{R}$, Chen GX. Molecular Typing of CTX-M-Producing Escherichia coli Isolates from Environmental Water, Swine Feces, Specimens from Healthy Humans, and Human Patients Appl Environ Microbiol. 2013; 79(19):5988-5996.

28. Al-Agamy MH, Shible AM, Hafez MM, AL-Ahdal MN, Memish ZA, Khubnani $H$. Molecular characteristics of extendedspectrum-producing Escherichia coli in Riyadh: emergence of CTX-M-15-producing Escherichia coli ST131. Annals Clin Microbiol Antimicrob. 2014; 13(4): 1-7.

29. Choi MJ, Lim SK, Jung SC, Ko KS. Comparison of CTX-Mproducing Escherichia coli isolates from humans and animals in South Korea. J Bacteriol Virol. 2014; 44 (1): 44-51.

30. Bonnedahl J, Drobni M, Gauthier-Clerc M, Hernandez J, Granholm S, Kayser Y, Melhus A, Kahlmeter G, Waldenström J, Johansson A, Olsen B. Dissemination of Escherichia coli with CTX-M type ESBL between humans and yellow-legged gulls in the South of France. PloS One 2009; 4: e5958.

31. Overdevest I, Willemsen I, Rijnsburger M, Eustace $A, X u L$, Hawkey P, Heck M, Savelkoul P, Vandenbroucke-Grauls C, van der Zwaluw K, Huijsdens X, Kluytmans J. Extended-spectrum $\beta$-lactamase genes of Escherichia coli in chicken meat and humans, the Netherlands. Emerg Infect Dis. 2011; 17: 12161222.

32. Stokes MO, Cottell JL, Piddock LJ, Wu G, Wootton M, Mevius DJ, Randall LP, Teale CJ, Fielder MD, Coldham NG. Detection and characterization of pCTlike plasmid vectors for blaCTX-M-14 in Escherichia coli isolates from humans, turkeys and cattle in England and Wales. J Antimicrob Chemother 2012; 67: 16391644

\section{Comment on this article:}

\section{(f) (B) in $8+\mathbf{S} P$}

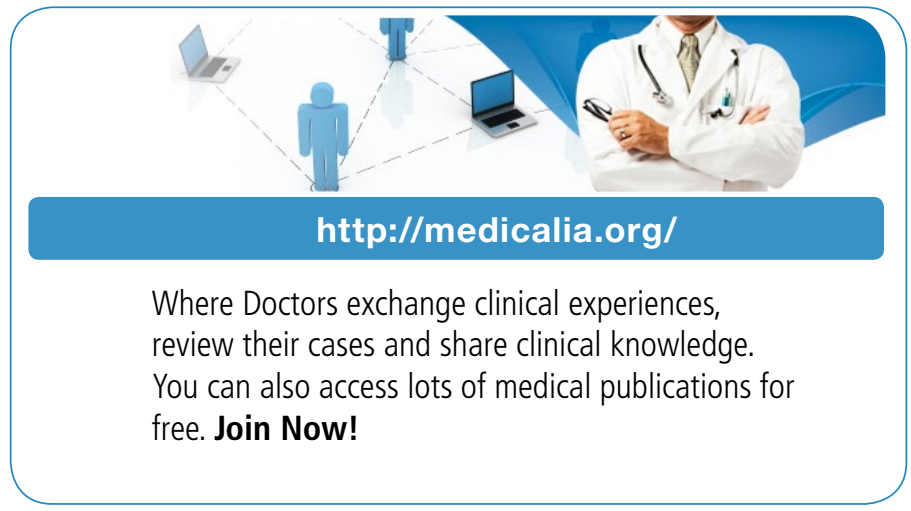

\section{Publish with iMedPub}

http://www.imed.pub

The Journal is an open access peer-reviewed journal that publishes scientific papers about all aspects of antimicrobials. The journal will publish original research articles, reviews, brief reports and case reports dealing with basic and clinical antibacterial agents, antiviral, antiprotozoals, antituberculuous, antifungal and antihelminthes agents.

All manuscripts must be prepared in English, and are subject to a rigorous and fair peer-review process. Accepted papers will immediately appear online.

The journal aims to advance the knowledge, attitude and the research of chemotherapy in the Arabic world in cooperation with international, national scientific and public societies as well as research centers with similar aims and objectives. 